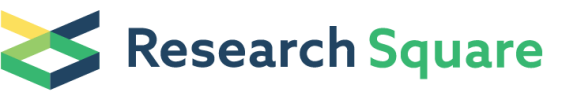

\section{Climate, Land use and Plant Richness Differently Shape Herbivory on Major Plant Functional Groups}

\section{Ute Fricke ( $\nabla$ ute.fricke@uni-wuerzburg.de )}

Julius Maximilians University Würzburg: Julius-Maximilians-Universitat Wurzburg https://orcid.org/0000-0002-5284-4518

\section{Sarah Redlich}

Julius Maximilians University Würzburg: Julius-Maximilians-Universitat Wurzburg

Jie Zhang

Julius Maximilians University Würzburg: Julius-Maximilians-Universitat Wurzburg

\section{Cynthia Tobisch}

University of Applied Sciences Weihenstephan Triesdorf: Hochschule Weihenstephan-Triesdorf

\section{Sandra Rojas-Botero}

Technical University Munich: Technische Universitat Munchen

\section{Caryl Benjamin}

Technical University Munich: Technische Universitat Munchen

\section{Jana Englmeier}

Julius Maximilians University Würzburg: Julius-Maximilians-Universitat Wurzburg

\section{Cristina Ganuza}

Julius Maximilians University Würzburg: Julius-Maximilians-Universitat Wurzburg

\section{Rebekka Riebl}

Bayreuth University: Universitat Bayreuth

\section{Johannes Uhler}

Julius Maximilians University Würzburg: Julius-Maximilians-Universitat Wurzburg

\section{Lars Uphus}

Technical University Munich: Technische Universitat Munchen

\section{Jörg Ewald}

University of Applied Sciences Weihenstephan Triesdorf: Hochschule Weihenstephan-Triesdorf

Johannes Kollmann

Technical University Munich: Technische Universitat Munchen

Ingolf Steffan-Dewenter

Julius Maximilians University Würzburg: Julius-Maximilians-Universitat Wurzburg

\section{Research Article}


Keywords: Ecosystem functions, habitat types, landscape diversity, plant guilds, plant-insect interactions

Posted Date: November 15th, 2021

DOI: https://doi.org/10.21203/rs.3.rs-1016363/v1

License: (c) (i) This work is licensed under a Creative Commons Attribution 4.0 International License. Read Full License 
2 Climate, land use and plant richness differently shape herbivory on major plant functional groups

\section{Authors $^{1}$}

4 Ute Fricke $^{1 *}$, Sarah Redlich ${ }^{1}$, Jie Zhang ${ }^{1}$, Cynthia Tobisch ${ }^{2,3}$, Sandra Rojas-Botero ${ }^{3}$, Caryl S. Benjamin ${ }^{4}$,

5 Jana Englmeier ${ }^{5}$, Cristina Ganuza ${ }^{1}$, Rebekka Riebl ${ }^{6}$, Johannes Uhler ${ }^{5}$, Lars Uphus ${ }^{4}$, Jörg Ewald ${ }^{2}$, Johannes

6 Kollmann $^{3}$, Ingolf Steffan-Dewenter ${ }^{1}$

$7{ }^{1}$ Department of Animal Ecology and Tropical Biology, Biocenter, University of Würzburg, Würzburg,

8 Germany

$9 \quad{ }^{2}$ Institute for Ecology and Landscape, Weihenstephan-Triesdorf University of Applied Sciences, Freising,

10 Germany

$11{ }^{3}$ Chair of Restoration Ecology, School of Life Sciences, Technical University of Munich, Freising,

12 Germany

$13{ }^{4}$ Ecoclimatology, TUM School of Life Sciences, Technical University of Munich, Freising, Germany

$14{ }^{5}$ Field Station Fabrikschleichach, Department of Animal Ecology and Tropical Biology, University of

15 Würzburg, Rauhenebrach, Germany

$16{ }^{6}$ Professorship of Ecological Services, Bayreuth Center of Ecology and Environmental Research

17 (BayCEER), University of Bayreuth, Bayreuth, Germany

18 *corresponding author: ute.fricke@uni-wuerzburg.de

\footnotetext{
${ }^{1}$ Authors' contribution: UF, SR and ISD conceived the idea of this manuscript. UF, JZ, CT, SRB, JEwald, JK and ISD designed the methodology. UF, SR, JZ, CT, SRB, CB, JEnglmeier, CG, RR, JU and LU collected data. UF analysed the data. UF wrote the first manuscript draft in consultation with SR and ISD. All authors commented critically on the manuscript and approved its final version.
} 
Abstract

Interactions between plants and herbivorous invertebrates drive the nutritional quality of resources for

21 higher trophic levels, nutrient cycling and plant-community structure. Thereby, shifts in functional

22 composition of plant communities particularly impact ecosystem processes. However, the current

23 understanding of herbivory is limited concerning climate, land use and plant richness, as comparative

24 studies of different plant functional groups are lacking. This study was conducted on 81 plots covering large

25 climatic and land-use gradients in Bavaria, Germany. We investigated foliar invertebrate herbivory rates

26 (proportional leaf-area loss, following 'herbivory') in three major plant functional groups (legumes, non-

27 leguminous forbs, grasses). As drivers we considered multi-annual mean temperature (range: $6.5-10.0^{\circ} \mathrm{C}$ ),

28 local habitat type (forest, grassland, arable field, settlement), local plant richness (species and family level, 29 ranges: 10-50 species, 5-25 families) and landscape diversity (0.2-3-km scale). Our results largely confirm 30 higher herbivory on legumes than on forbs and grasses. However, herbivory in forests was similar across 31 plant functional groups since herbivory on legumes was low, e.g. lower than on legumes in grasslands. We 32 also observed differential responses of herbivory among plant functional groups in response to plant 33 richness (family level only), but not to landscape diversity. Temperature did not affect overall herbivory, 34 but in grasslands higher temperature decreased herbivory on legumes and increased on forbs and grasses. 35 We conclude that climate, habitat type and family-level plant richness likely assert different effects on 36 herbivory among plant functional groups. This emphasises the importance of functional groups for 37 understanding community-level herbivory and ecosystem functioning.

\section{Keywords}

Ecosystem functions, habitat types, landscape diversity, plant guilds, plant-insect interactions 
41 Herbivores feeding on living plant tissue make essential contributions to ecosystem functioning

42 (Biedermann et al. 2005). When becoming prey or through defecating, herbivores provide nutrients to other 43 trophic levels and release nutrients which otherwise would be retained in plant material for a longer time.

44 Despite its key role in food webs and nutrient cycles, herbivory generally causes negligible total biomass 45 loss (Schowalter 2016). Nonetheless, herbivory affects growth, phenology, productivity and competitive 46 ability of individual plants (Crawley 1989; Schowalter 2016). Therefore, different intensities of herbivory 47 on neighbouring plants bear the potential to alter plant community composition (Crawley 1989; Kempel et al. 2015; Schowalter 2016). Shifts in plant community composition - particularly with respect to plant 49 functional groups (e.g. legumes, grasses) - may in turn affect ecosystem's productivity, plant total nitrogen 50 content, top-soil moisture and associated arthropod communities (Tilman et al. 1997; Siemann et al. 1998;

51 Fischer et al. 2019; Barneze et al. 2020). In many ecosystems, insect herbivores are among the major 52 contributors to herbivory (Schowalter 2016). Thus, a deeper understanding of the environmental drivers 53 affecting insect herbivory (in this study addressed by invertebrate herbivory) on plant functional groups is 54 pivotal to mitigate detrimental consequences for ecosystem functioning under anthropogenic climate and 55 land-use change.

56 Herbivory pressure strongly depends on the nutritious quality and palatability of plants (Loranger et al. 57 2012; Njovu et al. 2019), which varies substantially among major plant functional groups - namely 58 legumes, non-leguminous forbs and grasses (Scherber et al. 2006). Legumes contain more nitrogen, e.g. 59 higher crude plant protein content and lower leaf C:N ratio, than forbs and grasses (Perez Corona et al. 60 1995; Leingärtner et al. 2014), whereas lignin content is higher in grasses (Perez Corona et al. 1995). 61 Consequently, high, medium and low foliar herbivory intensities are frequently observed on legumes, non62 leguminous forbs and grasses, respectively (Scherber et al. 2006; Leingärtner et al. 2014). Furthermore, 63 plant functional groups encompass food plants of specialist herbivores since insect herbivores are often 
64 specialized in feeding within plant genera or families (Haddad et al. 2001). Therefore, different herbivore

65 species may be involved in herbivory among plant functional groups.

66 Temperature impacts life cycles, population dynamics and geographic distributions of invertebrate

67 herbivores and their interaction partners, such as plants and natural enemies (Bale et al. 2002; Rasmann and

68 Pellissier 2015). In warmer climates ectothermic invertebrates have relatively higher energy demands,

69 potentially resulting in uptake of resources with higher C:N ratios (Rasmann and Pellissier 2015; Malzahn

70 et al. 2016; Zhang et al. 2020). For instance, omnivores choose a more plant-based diet to meet changed

71 C:N demands at higher temperatures (Zhang et al. 2020). Yet our study is (among) the first to investigate

72 whether higher temperatures may also trigger invertebrate herbivores to shift diet away from legumes (low

$73 \mathrm{C}: \mathrm{N}$ ratio) towards plants with higher $\mathrm{C}: \mathrm{N}$ ratios, such as non-leguminous forbs and grasses.

74 Local drivers such as plant richness and habitat type affect herbivory. However, both positive (Ebeling et 75 al. 2014, Loranger et al. 2014, Dinnage 2013) and negative (Jactel and Brockerhoff 2007) effects of plant 76 species richness on herbivory have been reported. The degree of plant phylogenetic diversity, which can be 77 approximated by plant richness at family level (= plant familial richness), may serve as an explanation for 78 contrasting effects of plant species richness on herbivory (Dinnage 2013). Besides, herbivory depends on 79 the surrounding habitat. While larger impacts of herbivores were reported for herbaceous plants in open 80 rather than forested habitats (Maron and Crone 2006), studies comparing a large range of typical habitat 81 types in temperate regions (forest, grassland, arable field, settlement) are lacking.

82 High landscape diversity (Shannon Index) indicates the presence of more different habitat types, more 83 similar proportions of habitat types or both. This can increase richness and abundance of insect herbivores, 84 particularly of generalist species that benefit from resources of multiple habitats (Jonsen and Fahrig 1997). 85 Higher herbivore abundances, in turn, may increase intensity of herbivory (Ebeling et al. 2014; Njovu et al. 86 2019). 
87 Climate, land use and plant richness affect invertebrate herbivory, but knowledge is lacking on - potentially

88 differential - responses of herbivory among plant functional groups. Furthermore, this is the first study 89 comparing herbivory in a wide range of typical habitat types in temperate regions (forest, grassland, arable 90 field and settlement) across large climatic gradients, and also taking into account plant richness effects. In 91 particular, we addressed the following questions:

92 1. How do land use at local (habitat type) and landscape scale (landscape diversity), and local plant richness (at species and family level) affect invertebrate herbivory on plant functional groups? 


\section{Materials and methods}

$97 \quad$ Study area and plot selection

98 Research was conducted on 179 plots (complete data sets acquired for 81 plots) across Bavaria, Germany.

99 To disentangle the combined effects of climate and land use on herbivory in three different plant functional 100 groups, we used a novel multi-scale study design which combined climate zones, landscape-scale land-use 101 types, and a wide range of local habitat types (Redlich et al. 2021). Fifteen combinations of climate zones 102 (multi-annual mean temperature range of 81 plots: $6.5-10.0^{\circ} \mathrm{C}$ ) and landscape-scale land-use types (near103 natural, agriculture and urban) were chosen from $5.8 \mathrm{~km}$ x $5.8 \mathrm{~km}$ grid cells covering Bavaria, each with 104 four replicates (=60 'regions'). In each selected grid cell, plots were placed in three out of four possible 105 dominant, contrasting habitat types (forest, grassland, arable field, settlement) with at least $50 \mathrm{~m}$ distance 106 to larger roads and other habitat types. Furthermore, heat maps guided selection of plots with low correlation 107 between climatic and landscape-scale land-use variables (Redlich et al. 2021). Plots consisted of $30 \mathrm{~m} \times 3$ $108 \mathrm{~m}$ strips located on open herbaceous vegetation, such as forest glades and clearings, grazed, mown and 109 mulched grasslands, field margins and grasslands in proximity to crop fields, and parks and meadows within 110 settlement areas.

\section{Herbivory assessment}

112 Herbivory was measured in the plots once in the period from end-May until mid-June 2019 (spring season).

113 We assessed mean leaf-area loss by chewing invertebrates for three herbaceous plant functional groups:

114 legumes, non-leguminous forbs (following 'forbs') and grasses. Legumes contained representatives of the 115 plant family Fabaceae only. Forbs encompassed species of various herbaceous angiosperm families except 116 for the plant family Fabaceae and for plant families within the order Poales. Grasses included graminoids 117 of the plant family Poaceae and occasionally species of the Cyperaceae family. These three plant functional 118 groups are commonly distinguished due to their differences in several traits and their effect on ecosystem 
processes (Roscher et al. 2004), sometimes additional groups are distinguished e.g. small and tall forbs

120 (Scherber et al. 2006, Fischer et al. 2019) or $\mathrm{C}_{3}$ and $\mathrm{C}_{4}$ grasses (Siemann et al 1998).

121 Per plant functional group, three plant individuals of three plant species were randomly selected for the 122 collection of three leaves (total of 27 plant individuals and 81 leaves per plot). Plant species assessed for 123 herbivory differed among plots, since not even a single plant species occurred across all plots (Table S1), 124 but represent herbivory of the local herbaceous vegetation. Leaves from the apical, middle and basal nodes 125 of each plant were pinched off, mounted in a notebook with transparent tape, pressed and dried for later 126 assessment. Both leaf position as selection criterion and digital assessment in the lab were chosen to 127 minimize observer bias and also to include leaves of different ontogenetic stages that may be 128 disproportionately affected by herbivory (Sand-Jensen et al. 1994). Mean leaf-area loss was determined 129 using the BioLeaf app (Machado et al. 2016), which automatically transforms colour images to binary 130 images (only black and white pixels) and calculates proportional mean leaf-area loss based on white parts 131 enclosed by black leaf area. Therefore, some prior image adjustments were needed: i) Nibbled leaf margins 132 were straightened or adjusted to restore the pre-damage leaf contour with a thin black line in order to capture 133 nibbled leaf margins as missing leaf area; and ii) overlapping leaf parts were separated with a thin white 134 line connecting the white space to the surroundings of the leaf to not falsely be assigned as missing leaf 135 area by the Bioleaf app. Images were adjusted using GIMP software (The GIMP Development Team 2017).

\section{$136 \quad$ Measures of plant richness}

137 Vegetation surveys were conducted between May and July 2019 (seven subplots on each plot, adding up to $13810 \mathrm{~m}^{2}$ total sampling area per site). Recorded plant species and families were summed up per plot to achieve 139 plant richness at species and family level. Ferns, horsetails and woody plants as part of the herb layer were 140 considered for total plant richness measures but not for herbivory assessment. A list of plant species and 141 families present on plots can be found in the supplement (Table S1). 
144 and settlement).

145 At landscape-scale, we calculated landscape diversity as Shannon Index from detailed land-cover maps

146 distinguishing six land-use categories: natural/semi-natural, forest, grassland, arable field, settlement and 147 water (combination of ATKIS 2019, CORINE 2018 and IACS 2019; for details see Fig. S1). Since different 148 insect species can be affected by landscape-scale land use at various spatial scales (Thies et al. 2003; 149 Chaplin-Kramer et al. 2011), we included landscape diversity at multiple scales $(0.2 \mathrm{~km}, 0.5-3.0 \mathrm{~km}$ in 0.5 $150 \mathrm{~km}$ steps; seven spatial scales) around the centre point of the plots.

$151 \quad$ Measure of climate (temperature)

152 We retrieved 30-year multi-annual mean temperatures per plot based on gridded monthly averaged mean 153 daily air temperatures with a horizontal resolution of $1 \mathrm{~km}$ from 1981-2010 (Deutscher Wetterdienst 2020).

154 This climate variable was chosen to study climate and land-use effects in a space-for-time framework (Blois 155 et al. 2013, Redlich et al. 2021).

156 Data analysis

157 Proportional mean leaf-area loss data were averaged per plant individual, plant species and plant functional 158 group for each plot to equally account for individuals and species despite missing leaves and plant 159 individuals (e.g. nine leaves available of one plant species but only seven leaves of another). This approach 160 was favoured over a multiple-nested random term accounting for nested sampling structure (plant functional 161 group, species, individual, leaf position) to avoid model fitting issues in the presence of missing values.

162 Missing leaves occurred due to processing damage (e.g. dry leaf clung to opposite page and broke in 163 multiple pieces) or unidentifiable third leaves belonging to the same plant individual (e.g. bottom grass leaf 164 in dense vegetation). Missing plant species or individuals occurred when too few species or individuals 165 were available in a plot or, exceptionally, also due to processing damage. To minimize bias through single 166 herbivory events and to assure sampling of at least two different plant species per plant functional group, 
167 we excluded data from all plots of which we obtained proportional mean leaf-area loss data of $<10$ leaves 168 of each plant functional group prior to herbivory analysis. Taking also seven plots into account where no 169 herbivory sampling could be realized due to time constraints, this yielded 81 plots in 40 regions.

170 Herbivory data were analysed with beta regression to cope with continuous proportional data 171 (Yellareddygari et al. 2016; Douma and Weedon 2019). In preparation of beta regression, zeros were 172 replaced through a small value (0.00001; slightly lower than the smallest value) to allow for model 173 comparison with Akaike's information criterion (AIC), which is inappropriate for scaled data (Douma and 174 Weedon 2019). Proportional mean leaf-area loss data on legumes and forbs contained only a single zero 175 and data on grasses two zeros $(2.5 \%)$.

176 As candidate predictors, we included plant functional group, multi-annual mean temperature as climatic 177 variable, land use at local (habitat type) and landscape-scale (landscape diversity; seven spatial scales in 178 separate models), and local plant richness (species and family level). Predictor values were z-transformed 179 prior to analysis, while the selected best models are presented with untransformed predictor variables. Ten 180 separate models were created, each of them containing plant functional group, multi-annual mean 181 temperature, one of the four land-use and plant-richness variables (at different spatial scales, if applicable) 182 and all interactions up to the three-way interaction term. Separate models were preferred over one model 183 containing all land-use and plant-richness variables to avoid over-parameterization.

184 The model including the three-way interaction of plant functional group, multi-annual mean temperature 185 and habitat type indicated a trend in grassland, which was further explored using a data subset of grassland 186 plots. An additional model containing multi-annual mean temperature, habitat type and their interaction 187 term was fitted to the subset with the rest of the analysis approach being equal to that of the other models.

188 A nested random term for 'plot' in 'region' (three plots per region) was included to account for plant 189 functional groups on the same plots and clustering of plots, which were located in closer vicinity than other 
plots due to the nestedness of the study design (Redlich et al. 2021). This nested random term was retained

191 throughout the model selection process (Bolker et al. 2008).

192 The majority of maximum variance inflation factors were $<4$, which falls below the commonly applied 193 threshold for collinearity of variance inflation factor $>10$ (Chatterjee and Price 1991). The few cases in 194 which the variance inflation factor exceeded the threshold were in models containing interaction terms with 195 habitat type. Additionally, a correlation matrix of continuous predictor variables was calculated (Table S2) 196 and continuous predictors were plotted by habitat type (Fig. S2) to visually assess relationships between 197 continuous and categorical predictor variables. Continuous predictors were not or only weakly correlated 198 except for a strong positive correlation between plant richness at species and family level (Pearson's $\mathrm{r}=$ $1990.76, P<0.001$, Table S2) and both plant richness measures were highest in forest habitats (Fig. S2).

200 Models with all possible predictor combinations were compared by the goodness of fit based on Akaike's 201 information criterion corrected for small sample size (AICc). The lower AICc, the better the relative 202 goodness of model fit. Competing multivariate models with a difference of less than two $(\Delta \mathrm{AICc}<2)$ were 203 considered equal (Burnham and Anderson 2002), and then the more parsimonious model was chosen. 204 Model selection of fixed effects (predictors) was done with models fitted by maximum likelihood, while 205 the selected best model was fitted and is presented by restricted maximum likelihood (Zuur et al. 2009). 206 Tukey posthoc analysis was used to compare herbivory between levels of categorical variables (i.e. plant 207 functional groups, habitat types) and to correct for multiple comparisons.

208 Data analysis was done with R version 4.0.3 (R Core Team 2020) using the packages 'glmmTMB' (Brooks 209 et al. 2017), ‘emmeans' (Russell 2020), 'Hmisc' (Harrell 2020), 'MuMin' (Barton 2020), 'ggeffects' 210 (Lüdecke 2018), 'DHARMa' (Hartig 2020), and 'performance' (Lüdecke et al. 2020). 


\section{Results}

213 Effects of plant functional group, land-use and plant-richness on herbivory

214 We observed an overall proportional leaf-area loss due to invertebrate chewing across plant functional 215 groups of $1.35 \pm 0.10 \%$ (mean \pm se). Foliar herbivory on legumes was on average 2.3 times higher than on

216 forbs and 5.4 times higher than on grasses (Fig. 1a). Besides, plant functional group and habitat type 217 interactively affected herbivory (Fig. 1b). Herbivory on legumes was higher than herbivory on forbs except 218 in forests, where herbivory on legumes and forbs was similar. In forests, herbivory on legumes was also 219 lower than in grassland, and intermediate in settlements and agricultural fields. Herbivory on forbs and 220 grasses was similar across all habitat types.

221 Invertebrate herbivory did not depend on plant richness at species level (Fig. 2a). However, with increasing 222 total numbers of plant families, herbivory on legumes decreased while herbivory on forbs and grasses 223 increased (Fig. 2b). At the landscape-scale, invertebrate herbivory was similar across the covered landscape224 diversity gradient (Fig. 2; Table S3).

225 Interactive effects of plant functional group, climate and land-use (or plant richness) predictors on herbivory

226 Mean-annual temperature did not substantially affect overall herbivory and three-way interactions of plant 227 functional group, climate and single land-use or plant richness predictors were not supported by $\Delta$ AICc and 228 parsimony (Fig. 3, Table S3). Yet in grasslands, herbivory on legumes, forbs and grasses decreased, 229 increased and slightly increased with higher multi-annual mean temperature, respectively (Fig. 3, dashed 230 line: grassland subset, Table S4). 


\section{Discussion}

233 In this study, we compared herbivory among three major plant functional groups in a wide range of typical

234 habitat types in temperate regions across large climatic gradients, and also taking into account land use at

235 local and landscape scale, and local plant richness. Herbivory differed between plant functional groups and

236 local habitat types as well as with plant richness at family level, but showed no significant response to plant

237 richness at species level, landscape diversity and multi-annual mean temperature at the studied gradients,

238 except for differential temperature effects among plant functional groups in grasslands (significant effect

239 in grassland subset).

How do land use and plant richness affect invertebrate herbivory on plant functional groups?

241 Although herbivory assessment was conducted on open herbaceous vegetation, the surrounding local

242 habitat types included in this study differ in multiple aspects that may impact invertebrate herbivores.

243 Among habitat types, we did not observe differences in herbivory on forbs and grasses but herbivory on

244 legumes was lower in forests than in grasslands and intermediate in settlements and arable fields. Higher

245 impact of herbivores on herbs in grasslands than forests - not differentiating plant functional groups - was

246 also reported by Maron et al (2006). Our results, however, suggest that herbivory on legumes is more

247 sensitive to local land use (habitat type) than that on forbs and grasses, which emphasises the importance

248 of distinguishing between plant functional groups. One explanation could be that legumes are more prone

249 to specialist herbivory and that herbivore communities on herbaceous-vegetation patches in forests may

250 more frequently lack these herbivore species, since forests may constitute barriers to dispersal (Schmitt et

251 al. 2000) and since small, isolated patches face higher species extinction risk at simultaneously reduced

252 recolonization rate (Rösch et al. 2013). In analogy, highest herbivory intensities on legumes in grasslands

253 may result from larger habitat patches and fewer dispersal barriers. An even simpler explanation of the

254 observed herbivory pattern on legumes provides the 'habitat amount hypothesis' put forth by Fahrig (2013).

255 This hypothesis stresses the importance of the total amount of habitat area for species richness (across a

256 broad taxonomic range, including insects). Thus, more herbaceous vegetation in grasslands than forests 
may have led to higher species richness of herbivores foraging on herbaceous plants and indirectly to higher herbivory rates on legumes, under the assumption that higher herbivore species richness increases the likelihood that herbivore species specialized on legumes are present.

260 While herbivory on legumes differed among habitat types, we observed similar herbivory among habitat types on grasses and forbs. Herbivory on grasses was commonly low, thus when small habitat-type effects occurred, they may have been rendered invisible. Forbs encompass species of several plant families, which increases the likelihood that some of the forb plant families perceive herbivore damage. This suggests to differentiate between more groups of forbs, e.g. distinguishing herbivory on plant-family level for forbs or distinguishing small and tall forbs (see also Roscher et al. 2004). Alternatively, forbs and grasses may be prone to more generalist herbivores, which have the potential to maintain herbivory even at low (generalist

267 herbivore) species number (Rossetti et al. 2017). Further research should elaborate on linking functional 268 invertebrate community compositions, e.g. degree of herbivore generality (Shinohara and Yoshida 2021), to herbivory on plant functional groups (differentiating several groups of forbs) in different habitat types 270 for a deeper understanding of herbivory.

271 Plant richness at family level - but not at species level - decreased herbivory on legumes and increased 272 herbivory on non-leguminous forbs and (slightly on) grasses. Since herbivores are often specialized on 273 feeding within plant families (Bernays and Graham 1988; Haddad et al. 2001), resource concentration and 274 dilution effects are likely stronger at family level. Nonetheless, small effects of plant richness at family 275 level on herbivory on grasses may result from generally very low herbivory intensity on grasses. In the 276 presence of more plant families, lower herbivory rates on legumes may be explained by the reduced 277 likelihood of specialist herbivores to find their host plant (Root 1973, 'resource concentration hypothesis'). 278 The increased herbivory on forbs (most species- and family-rich functional group) may result from an 279 increased likelihood of palatable plant families being among the forb species present. Family-level plant 280 richness differentially affecting herbivory among plant functional groups, and plant richness effects at 281 family level (higher taxonomic level) may explain contrasting plant species richness effects on herbivory 

2014).

284 Landscape diversity may elicit contrasting effects on invertebrate species - both herbivores and natural 285 enemies - depending on their needs or ability to exploit resources from multiple habitats (Jonsen and Fahrig 1997; Martin et al. 2013). However, our results indicate that herbivory at the level of plant functional groups seems to be largely independent of landscape diversity at various spatial scales. Since a small number of common generalist herbivore species have the potential to maintain herbivory (Rossetti et al. 2017), both herbivore and natural-enemy community composition may have changed without immediate changes visible in herbivory. Nevertheless, diverse landscapes may favour resilience of herbivory and predation (Oliver et al. 2015).

Do climate and land use jointly affect invertebrate herbivory among plant functional groups?

293 Although warmer climates are expected to increase herbivory pressure (Rasmann and Pellissier 2015), we 294 did not observe a general increase of herbivory in response to higher multi-annual mean temperature covered by our study design. In grassland habitats, however, herbivory on legumes decreased towards warmer climates, while herbivory increased on forbs and (slightly on) grasses. Differential climate effects occurring only in grasslands may result from microclimatic buffering effects in forests (De Frenne et al. 2019) and potentially overriding effects of anthropogenic disturbance (Danneyrolles et al. 2019) - in arable and settlement habitats. The observed pattern in grasslands may have multiple causes: i) Legume-specialist herbivores might be more sensitive to higher temperatures than generalists or specialists of the other plant

301 functional groups. ii) Metabolic needs of ectotherms may increase more quickly than feeding rate with 302 increasing temperature (Lee et al. 2015; Malzahn et al. 2016; Zhang et al. 2020) and thus generalist 303 invertebrate herbivores may shift from legumes to non-legumes to meet higher energy (less nitrogen) 304 demands. iii) Chemistry and efficacy of plant defences are subject to temperature effects (Lemoine et al. 305 2013; Havko et al. 2020), thus - potentially - plant defence efficacy may be higher or adapt more quickly 306 in legumes than forbs and grasses at higher temperature. More research will be needed to provide further 
307 evidence on differential rates of herbivory among plant functional groups towards higher temperature and 308 to identify the major drivers.

309 Conclusion

310 We conclude that multi-annual mean temperature, plant richness at family level and land-use at local scale

311 (habitat type) - but not at landscape scale (landscape diversity) - assert differential effects on herbivory

312 among plant functional groups, with legume herbivory in grasslands being most affected. Herbivory on

313 legumes was higher in grassland than forest habitats, decreased with temperature in grasslands, and

314 decreased with family-level plant richness. Further research is needed to identify the drivers behind these

315 observations, whereby functional herbivore community composition - along with plant functional groups

316 - may provide valuable insights. Our study emphasises the importance of functional groups (of both plants

317 and herbivores) for understanding the response of community-level herbivory and ecosystem functioning. 
320 We are grateful to the landowners, leaseholders, municipalities and the Bavarian State Forestry, who 321 facilitated this project. Special thanks go to Jan Weber and Kerstin Hikel for numerous hours spent on 322 herbivory assessment. We thank the Bavarian Office for Surveying and Geographic Information, the 323 European Environment Agency of the European Union under the framework of the Copernicus programme 324 and the Bavarian State Ministry of Agriculture and Forestry for providing ATKIS 2019, CORINE 2018 and 325 IACS 2019 land cover data, respectively. This study was conducted within the framework of the joint 326 project LandKlif (https://www.landklif.biozentrum.uni-wuerzburg.de/) funded by the Bavarian Ministry of 327 Science and the Arts via the Bavarian Climate Research Network (bayklif; https://www.bayklif.de). 


\section{Declarations}

330 Funding: Funding was received from the Bavarian Ministry of Science and the Arts via the LandKlif project

331 as part of the bayklif project

332 Conflicts of interest/Competing interests: The authors declare no conflicts of interest.

333 Ethics approval: Not applicable

334 Consent to participate: Not applicable

335 Consent for publication: Not applicable

336 Availability of data and material: We intend that data will be available from the Dryad Digital Repository.

337 Code availability: R Code is available from the corresponding author upon reasonable request. 


\section{References}

340 Bale JS, Masters GJ, Hodkinson ID, et al (2002) Herbivory in global climate change research: direct effects of rising temperature on insect herbivores. Glob Chang Biol 8:1-16. https://doi.org/10.1046/j.1365-2486.2002.00451.x

Barneze AS, Whitaker J, McNamara NP, Ostle NJ (2020) Legumes increase grassland productivity with no effect on nitrous oxide emissions. Plant Soil 446:163-177. https://doi.org/10.1007/s11104-019-

Barton K (2020) Multi-Model Inference. https://cran.r-project.org/package=MuMIn

347

348

349

Bernays E, Graham M (1988) On the evolution of host specificity in phytophagous arthropods. Ecology 69:886-892. https://doi.org/10.2307/1941237

Biedermann R, Achtziger R, Nickel H, Stewart AJA (2005) Conservation of grassland leafhoppers: a brief review. J Insect Conserv 9:229-243. https://doi.org/10.1007/s10841-005-0531-z

Blois JL, Williams JW, Fitzpatrick MC, et al (2013) Space can substitute for time in predicting climatechange effects on biodiversity. Proc Natl Acad Sci, 110:9374-9379. https://doi.org/10.1073/pnas.1220228110

Bolker BM, Brooks ME, Clark CJ, et al (2008) Generalized linear mixed models: a practical guide for ecology and evolution. Trends Ecol Evol 24:127-135. https://doi.org/10.1016/j.tree.2008.10.008

Brooks ME, Kristensen K, Benthem, Koen J. van Magnusson A, et al (2017) glmmTMB balances speed and flexibility among packages for zero-inflated generalized linear mixed modeling. R J 9:378-400. https://doi.org/10.32614/RJ-2017-066

Burnham KP, Anderson DR (2002) Model selection and multimodel inference: a practical informationtheoretic approach, 2nd edn. Springer 
361

Chaplin-Kramer R, O’Rourke ME, Blitzer EJ, Kremen C (2011) A meta-analysis of crop pest and natural enemy response to landscape complexity. Ecol Lett 14:922-932. https://doi.org/10.1111/j.14610248.2011.01642.x

Chatterjee S, Price B (1991) Regression Analysis by Example, 2nd edn. Wiley, New York

Crawley MJ (1989) Insect herbivores and plant population dynamics. Annu Rev Entomol 34:531-564. https://doi.org/10.1146/annurev.en.34.010189.002531

Danneyrolles V, Dupuis S, Fortin G, et al (2019) Stronger influence of anthropogenic disturbance than climate change on century-scale compositional changes in northern forests. Nat Commun 10:1-7. https://doi.org/10.1038/s41467-019-09265-z

De Frenne P, Zellweger F, Rodríguez-Sánchez F, et al (2019) Global buffering of temperatures under forest canopies. Nat Ecol Evol 3:744-749. https://doi.org/10.1038/s41559-019-0842-1

Deutscher Wetterdienst (2020) Multi-year temperature and precipitation data. https://opendata.dwd.de

Dinnage R (2013) Phylogenetic diversity of plants alters the effect of species richness on invertebrate herbivory. PeerJ 2013:1-24. https://doi.org/10.7717/peerj.93

Douma JC, Weedon JT (2019) Analysing continuous proportions in ecology and evolution: A practical introduction to beta and Dirichlet regression. Methods Ecol Evol 10:1412-1430. https://doi.org/10.1111/2041-210X.13234

Ebeling A, Meyer ST, Abbas M, et al (2014) Plant diversity impacts decomposition and herbivory via changes in aboveground arthropods. PLoS One 9:e106529. https://doi.org/10.1371/journal.pone.0106529

Fahrig L (2017) Ecological responses to habitat fragmentation per se. Annu Rev Ecol Evol Syst 48:1-23. https://doi.org/10.1146/annurev-ecolsys-110316-022612 
Fahrig L (2013) Rethinking patch size and isolation effects: the habitat amount hypothesis. J Biogeogr 40:1649-1663. https://doi.org/10.1111/jbi.12130

Fischer C, Leimer S, Roscher C, et al (2019) Plant species richness and functional groups have different effects on soil water content in a decade-long grassland experiment. J Ecol 107:127-141. https://doi.org/10.1111/1365-2745.13046

Haddad NM, Tilman D, Haarstad J, et al (2001) Contrasting effects of plant richness and composition on insect communities: A field experiment. Am Nat 158:17-35. https://doi.org/10.1086/320866

Harrell FE (2020) Hmisc: Harrell Miscellaneous. https://cran.r-project.org/package=Hmisc

Hartig F (2020) DHARMa: Residual diagnostics for hierarchical (multi-level/ mixed) regression mModels. https://cran.r-project.org/package=DHARMa

Havko NE, Kapali G, Das MR, Howe GA (2020) Stimulation of insect herbivory by elevated temperature outweighs protection by the jasmonate pathway. Plants 9:1-14. https://doi.org/10.3390/plants9020172

Jactel H, Brockerhoff EG (2007) Tree diversity reduces herbivory by forest insects. Ecol Lett 10:835848. https://doi.org/10.1111/j.1461-0248.2007.01073.x

Jonsen ID, Fahrig L (1997) Response of generalist and specialist insect herbivores to landscape spatial structure. Landsc Ecol 12:185-197. https://doi.org/10.1023/A:1007961006232

Kempel A, Razanajatovo M, Stein C, et al (2015) Herbivore preference drives plant community composition. Ecology 96:2923-2934. https://doi.org/10.1890/14-2125.1

Lee KP, Jang T, Ravzanaadii N, Rho MS (2015) Macronutrient balance modulates the temperature-size rule in an ectotherm. Am Nat 186:212-222. https://doi.org/10.1086/682072 
and elevation on nutritional quality and herbivory of alpine plants. PLoS One 9:e93881. https://doi.org/10.1371/journal.pone.0093881

407 Lemoine NP, Drews WA, Burkepile DE, Parker JD (2013) Increased temperature alters feeding behavior 408 of a generalist herbivore. Oikos 122:1669-1678. https://doi.org/10.1111/j.1600-0706.2013.00457.x

409

410

411

412

Loranger H, Weisser WW, Ebeling A, et al (2014) Invertebrate herbivory increases along an experimental gradient of grassland plant diversity. Oecologia 174:183-193. https://doi.org/10.1007/s00442-013$2741-5$

Loranger J, Meyer ST, Shipley B, et al (2012) Predicting invertebrate herbivory from plant traits:

Evidence from 51 grassland species in experimental monocultures. Ecology 93:2674-2682. https://doi.org/10.1890/12-0328.1

Lüdecke D (2018) ggeffects: Tidy data frames of marginal effects from regression models. J Open Source Softw 3:772. https://doi.org/10.21105/joss.00772

Lüdecke D, Makowski D, Waggoner P, Patil I (2020) performance: Assessment of Regression Models Performance. CRAN. https://doi.org/10.5281/zenodo.3952174

Machado BB, Orue JPM, Arruda MS, et al (2016) BioLeaf : A professional mobile application to measure foliar damage caused by insect herbivory. Comput Electron Agric 129:44-55. https://doi.org/10.1016/j.compag.2016.09.007

Malzahn AM, Doerfler D, Boersma M (2016) Junk food gets healthier when it's warm. Limnol Oceanogr 61:1677-1685. https://doi.org/10.1002//no.10330

Maron JL, Crone E (2006) Herbivory: effects on plant abundance, distribution and population growth. Proc R Soc B 273:2575-2584. https://doi.org/10.1098/rspb.2006.3587

Martin EA, Reineking B, Seo B, Steffan-Dewenter I (2013) Natural enemy interactions constrain pest control in complex agricultural landscapes. Proc Natl Acad Sci 110:5534-5539. 
Njovu HK, Peters MK, Schellenberger Costa D, et al (2019) Leaf traits mediate changes in invertebrate herbivory along broad environmental gradients on Mt. Kilimanjaro, Tanzania. J Anim Ecol 88:1777-1788. https://doi.org/10.1111/1365-2656.13058

Oliver TH, Heard MS, Isaac NJB, et al (2015) Biodiversity and resilience of ecosystem functions. Trends Ecol Evol 30:673-684. https://doi.org/10.1016/j.tree.2015.08.009

Perez Corona ME, Garcia Ciudad A, Garcia Criado B, Vazquez de Aldana BR (1995) Patterns of aboveground herbage production and nutritional quality structure on semiarid grasslands. Commun Soil Sci Plant Anal 26:1323-1341. https://doi.org/10.1080/00103629509369375

R Core Team (2020) R: A language and environment for statistical computing. https://www.r-project.org/

Rasmann S, Pellissier L (2015) Adaptive responses of plants to insect herbivores under climate change. In: Björkman C, Niemelä P (eds) Climate Change and Insect Pests. CABI, pp 38-53

Redlich S, Zhang J, Benjamin C, et al (2021) Disentangling effects of climate and land use on biodiversity and ecosystem services - a multi-scale experimental design. bioRxiv. https://doi.org/10.1101/2021.03.05.434036

Root RB (1973) Organization of a plant-arthropod association in simple and diverse habitats: The fauna of collards (Brassica oleracea). Ecol Soc Am 43:95-124

Rösch V, Tscharntke T, Scherber C, Batáry P (2013) Landscape composition, connectivity and fragment size drive effects of grassland fragmentation on insect communities. J Appl Ecol 50:387-394. https://doi.org/10.1111/1365-2664.12056

Roscher C, Schumacher J, Baade J, et al (2004) The role of biodiversity for element cycling and trophic interactions: An experimental approach in a grassland community. Basic Appl Ecol 5:107-121. https://doi.org/10.1078/1439-1791-00216 
451 Rossetti MR, Tscharntke T, Aguilar R, Batáry P (2017) Responses of insect herbivores and herbivory to 452 habitat fragmentation: a hierarchical meta-analysis. Ecol Lett 20:264-272.

453 https://doi.org/10.1111/ele.12723

454 Russell L (2020) emmeans: Estimated Marginal Means, aka Least-Squares Means. https://cran.r455 project.org/package $=$ emmeans

456 Sand-Jensen K, Jacobsen D, Duarte CM (1994) Herbivory and resulting plant damage. Oikos 69:545-

457

Scherber C, Mwangi PN, Temperton VM, et al (2006) Effects of plant diversity on invertebrate herbivory 549. https://doi.org/10.2307/3545870

460

Schmitt T, Varga Z, Seitz A (2000) Forests as dispersal barriers for Erebia medusa (Nymphalidae,

461 Lepidoptera). Basic Appl Ecol 1:53-59. https://doi.org/10.1078/1439-1791-00008

462

Schowalter TD (2016) Herbivory. In: Schowalter TD (ed) Insect Ecology, 4th edn. Academic Press, pp $405-443$

Shinohara N, Yoshida T (2021) Why species richness of plants and herbivorous insects do or do not correlate. Ecol Res 36:258-265. https://doi.org/10.1111/1440-1703.12189

466 Siemann E, Tilman D, Haarstad J, Ritchie M (1998) Experimental tests of the dependence of arthropod 467 diversity on plant diversity. Am Nat 152:738-750. https://doi.org/10.1086/286204

468 The GIMP Development Team (2017) GIMP. https://www.gimp.org

469 Thies C, Steffan-Dewenter I, Tscharntke T (2003) Effects of landscape context on herbivory and 470 parasitism at different spatial scales. Oikos 101:18-25. https://doi.org/10.1034/j.1600-

471 0706.2003.12567.x

472 Tilman D, Knops J, Wedin D, et al (1997) The influence of functional diversity and composition on 
474 Yellareddygari SK, Pasche JS, Taylor RJ, et al (2016) Beta regression model for predicting the 475 development of pink rot in potato tubers during storage. Plant Dis 100:1118-1124.

476 https://doi.org/10.1094/PDIS-06-15-0696-RE

477 Zhang P, Leeuwen CHA Van, Bogers D, et al (2020) Ectothermic omnivores increase herbivory in 478 response to rising temperature. Oikos 129:1028-1039. https://doi.org/10.1111/oik.07082

479 Zuur AF, Ieno EN, Walker NJ, et al (2009) Mixed Effects Models and Extensions in Ecology with R. $480 \quad$ Springer

481

482 


\section{Electronic supplementary material}

484 Additional supporting information may be found in the online version of this article:

485 Fig. S1 (+Text) Creation of detailed land-cover maps based on six main land-use types within Bavaria (semi-natural 486 habitat, forest, grassland, arable, urban, water). The map was created by combining three different land-cover maps 487 (ATKIS 2019, IACS 2019, CORINE 2018).

Fig. S2 Visual evaluation of relationships between the categorical predictor variable (habitat type) and the continuous predictor variables (a) multi-annual mean temperature, (b) species-level plant richness (= total plant species richness) and (c) family-level plant richness (= total plant familial richness) used for herbivory analysis.

Table S1 List of recorded plant species in vegetation survey and number of plots on which they occurred. Plant species list was used to derive plant richness measures (species and family level). Even though ferns, horsetails and woody plants as part of the herb layer are listed, these were not considered for herbivory assessment. No plant species occurred on all plots (= 179 plots).

Table S2 Pearson correlation coefficients for all continuous variables included in model selection processes on herbivory data (81 plots). Significant correlations based on $\alpha=0.05$ are indicated as following: $P<0.05^{*}, P<0.01^{* *}$, $P<0.001^{* * *}$

Table S3 Null, "full" and best beta mixed models on mean leaf area loss per plant functional group and plot. "Full" models include different sets of fixed effects but always include plant functional group, one climatic environmental variable, one land-use or plant-richness variable and their interaction terms. Fixed effects encompass: Plant functional group (Plant guild), multi-annual mean temperature (MAT), habitat type (habitat), species-level plant richness (specnum), family-level plant richness (famnum) and landscape diversity (LD) at multiple spatial scales. Continuous predictor variables were z-transformed (s-Fixed effect) prior to modelling. To account for study design, plot nested in region was added as random term. Asterisks $\left(^{*}\right)$ between fixed effects indicate that both, all main effects and all interaction terms were included. Bold font indicates the best model based on relative goodness of model fit (lowest AICc).

Table S4 Selection process of beta mixed models on mean leaf area loss per plant functional group and plot on data from grassland habitats only. Fixed effects encompass plant functional group (Plant guild) and z-transformed multiannual mean temperature (sMAT). To account for study design, plot nested in region was added as random term. Asterisks $\left(^{*}\right)$ between fixed effects indicate that both, main effects and all interaction terms were included. Relative 
511 goodness of model fit is indicated by Akaike's information criterion corrected for small sample size (AICc). Bold font

512 highlights the best model based on $\triangle \mathrm{AICc}<2$. 
513 Fig. 1 Mean leaf-area loss per plot (a) for each plant functional group and (b) habitat type and plant functional group.

514 Red diamonds highlight mean values. Lower case letters indicate differences between groups (plant functional groups

515 and habitat types) evaluated by post hoc tests with Tukey correction after evaluation of the overall effects in beta 516 regression models by $\triangle \mathrm{AICC}$ and parsimony.

517 Fig. 2 Mean leaf-area loss to invertebrate herbivory per plot and plant functional group (legumes: pink circles, non518 leguminous forbs: green triangles: grasses: blue squares) is presented across plant richness at (a) species level and 519 (b) family level, and (c) landscape diversity at 1-km spatial scale. Solid lines present predictions of best beta mixed 520 models. Model selection was based on $\triangle \mathrm{AICc}$ and parsimony.

521 Fig. 3 Mean leaf-area loss per plot and plant functional group (legumes: pink circles, non-leguminous forbs: green 522 triangles: grasses: blue squares) is presented per habitat type across the multi-annual mean temperature gradient. 523 Solid lines indicate predictions of the best beta mixed model based on the complete data set. Dashed lines show 524 predictions based on the grassland subset. Model selection was done using $\triangle \mathrm{AICc}$ and parsimony. 
Fig. 1
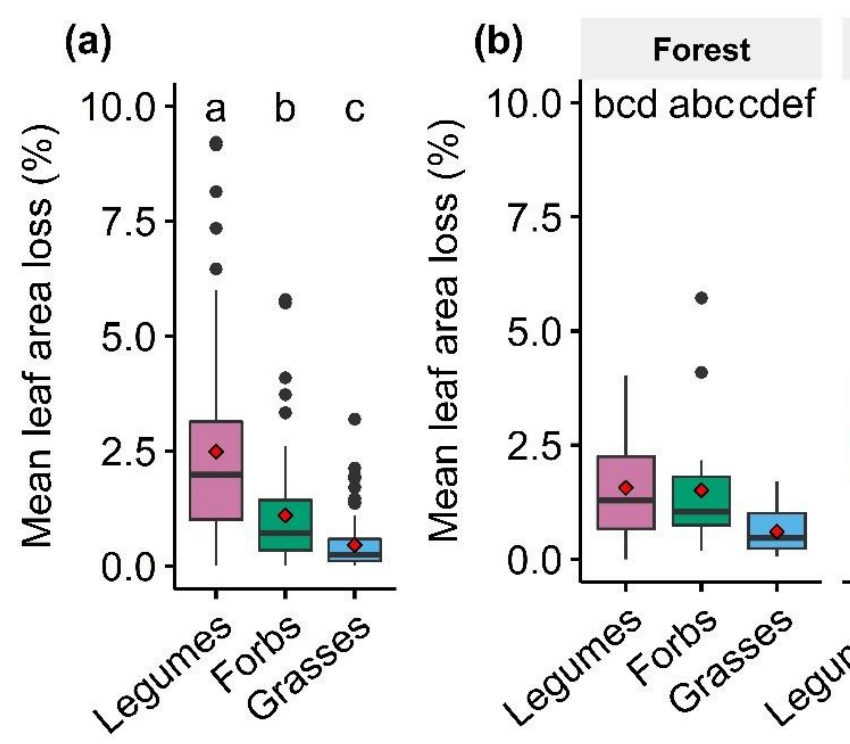

Grassland

Arable field

Settlement

ab bcdedef ab cdef ef

-

Plant functional group 


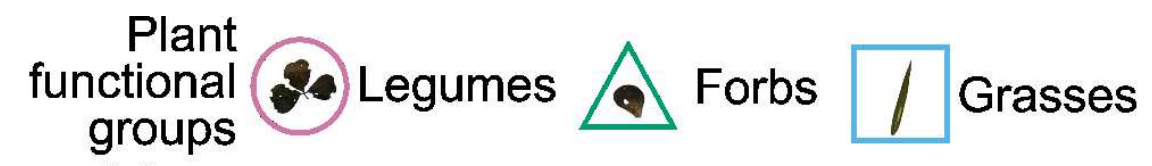

(a)
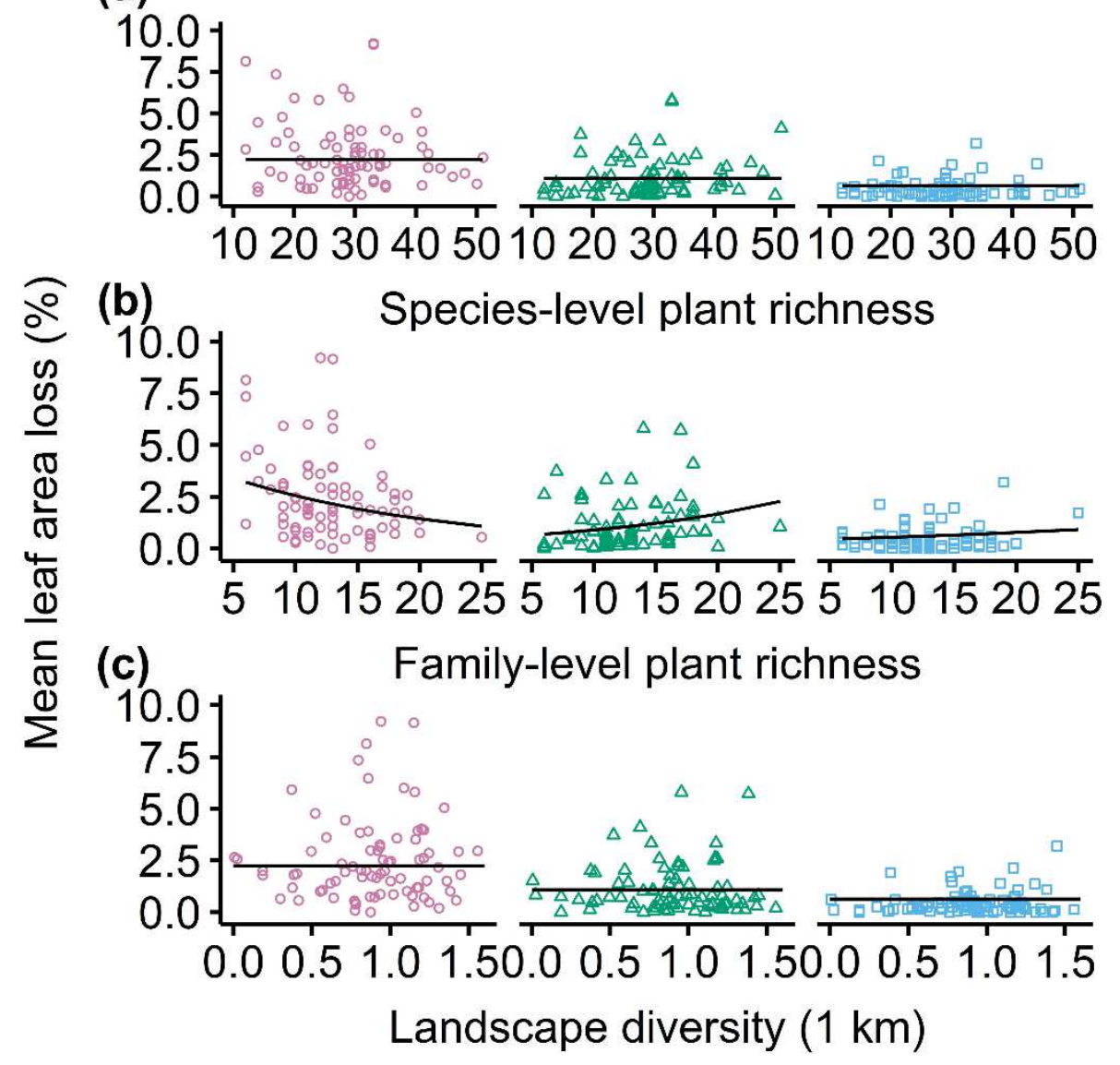


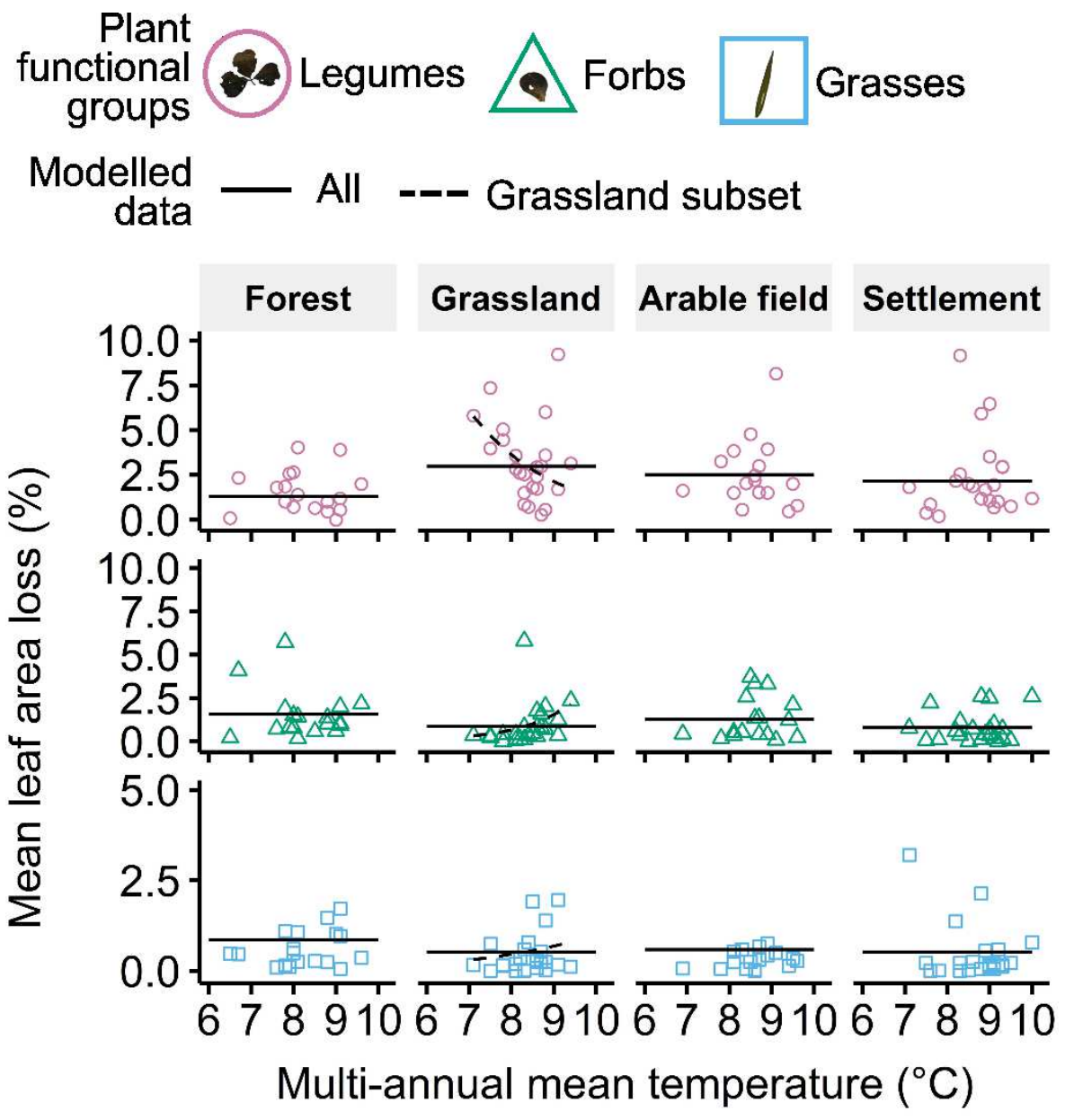


Figures

(a)

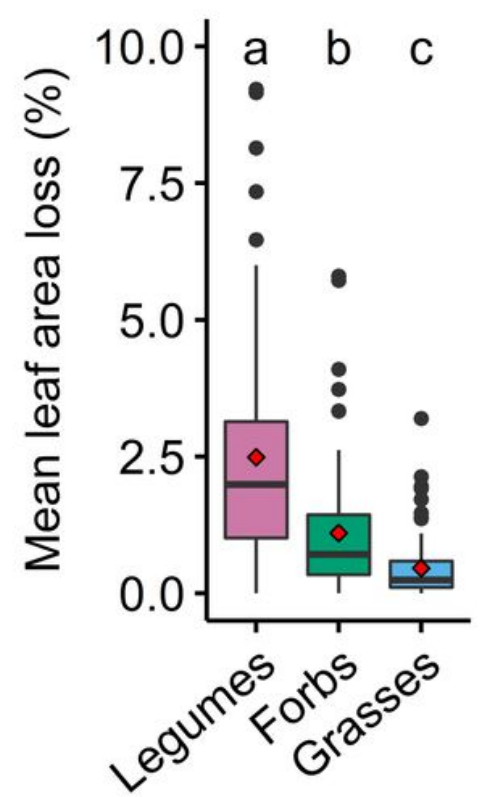

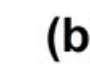

(b) Forest

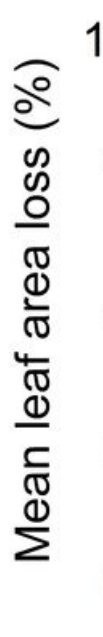

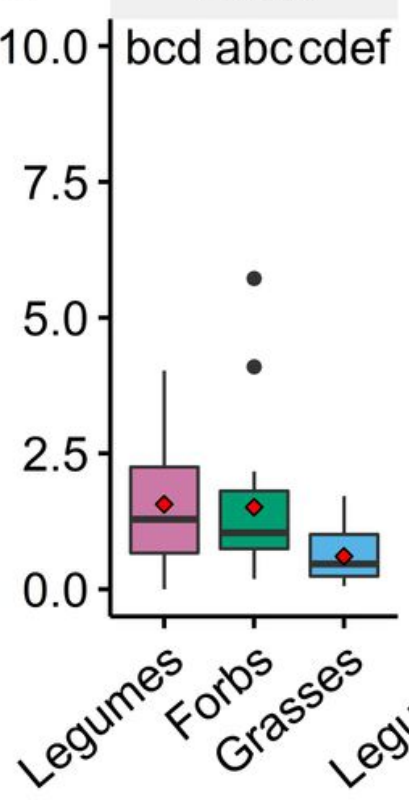

Grassland

a cdef $f$

(2)

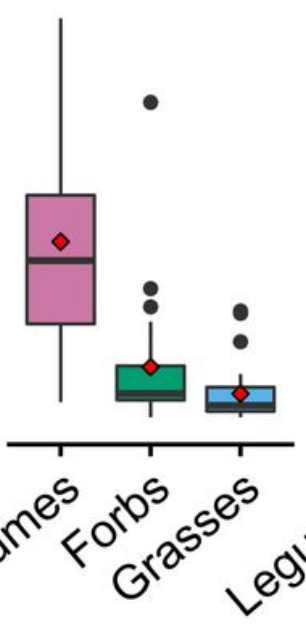

Arable field ab bcdedef

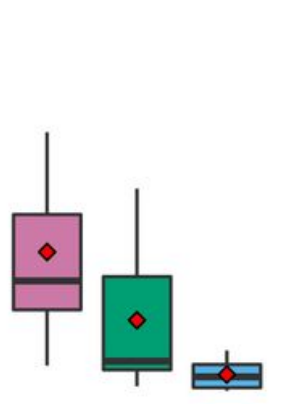

$\bullet$ Settlement

Plant functional group

Figure 1

Mean leaf-area loss per plot (a) for each plant functional group and (b) habitat type and plant functional group. Red diamonds highlight mean values. Lower case letters indicate differences between groups (plant functional groups and habitat types) evaluated by post hoc tests with Tukey correction after evaluation of the overall effects in beta regression models by $\triangle \mathrm{AICc}$ and parsimony. 


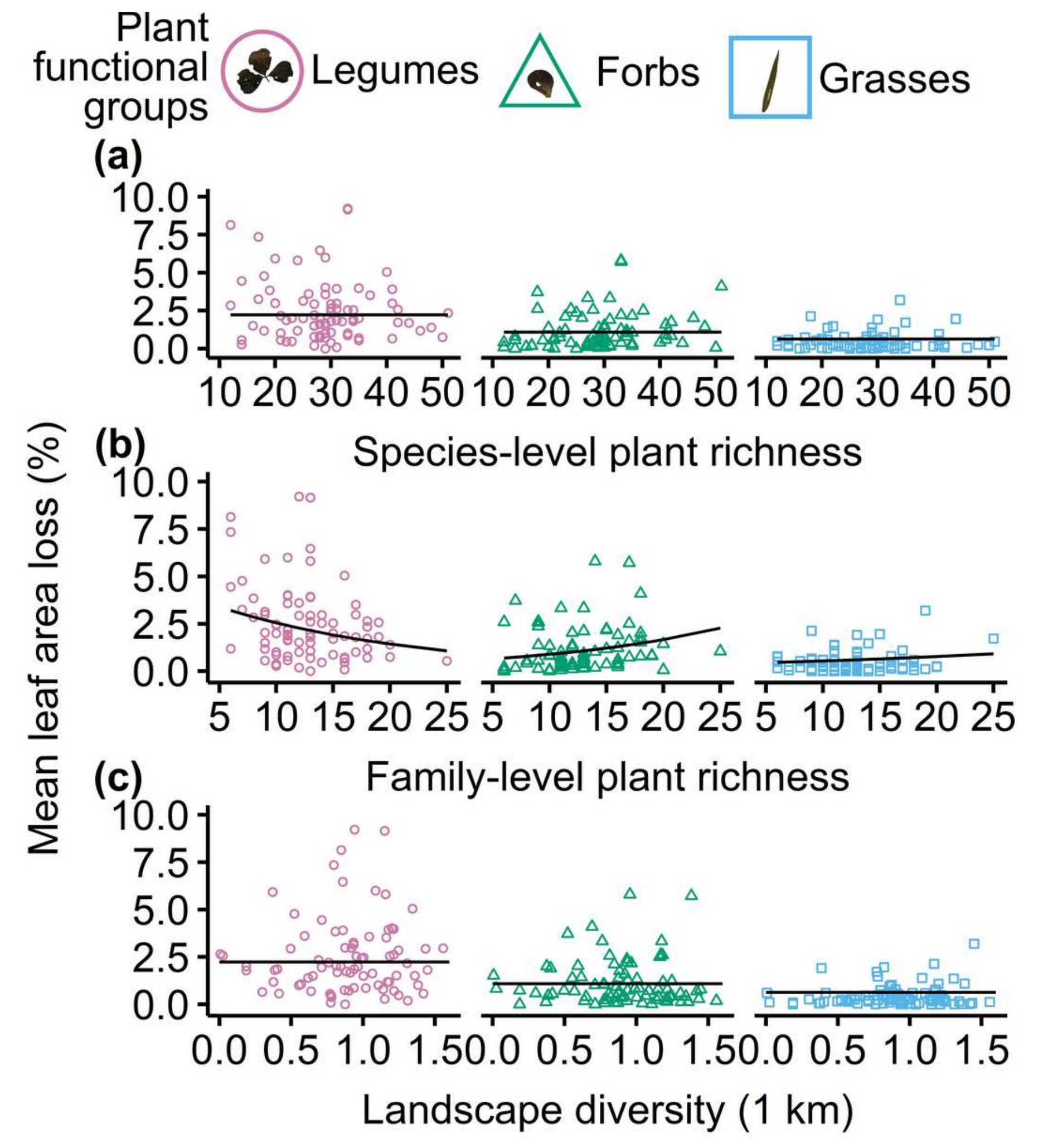

Figure 2

Mean leaf-area loss to invertebrate herbivory per plot and plant functional group (legumes: pink circles, non leguminous forbs: green triangles: grasses: blue squares) is presented across plant richness at (a) species level and (b) family level, and (c) landscape diversity at 1-km spatial scale. Solid lines present predictions of best beta mixed models. Model selection was based on $\triangle \mathrm{AICC}$ and parsimony. 


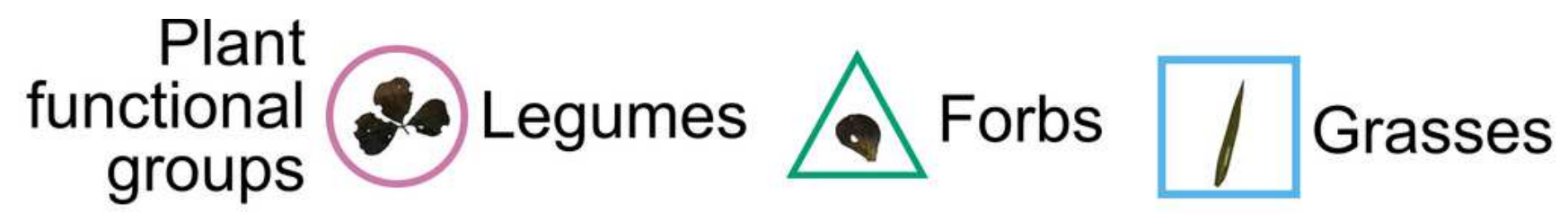
Modelled
data All --- Grassland subset

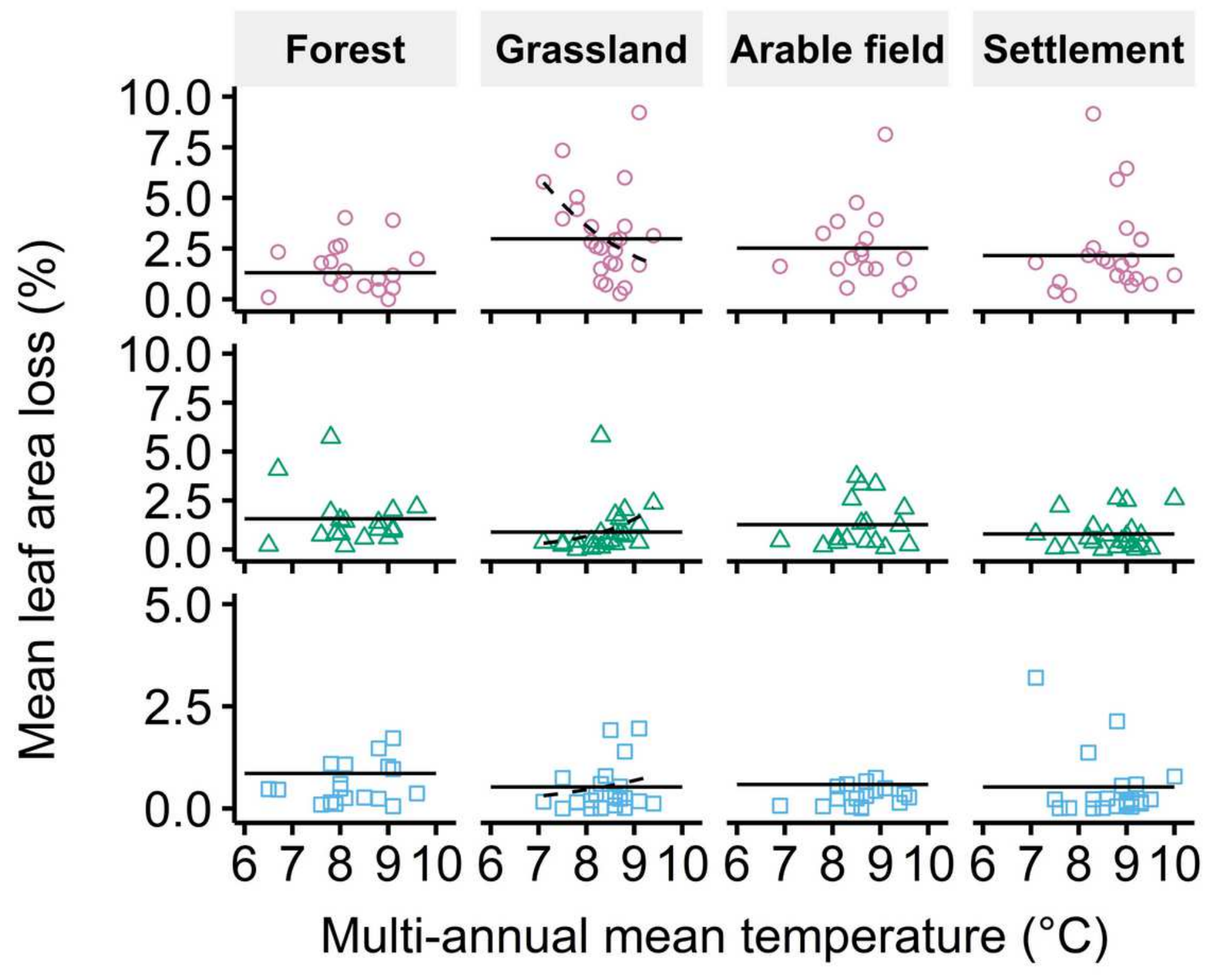

Figure 3

Mean leaf-area loss per plot and plant functional group (legumes: pink circles, non-leguminous forbs: green triangles: grasses: blue squares) is presented per habitat type across the multi-annual mean temperature gradient. Solid lines indicate predictions of the best beta mixed model based on the complete data set. Dashed lines show predictions based on the grassland subset. Model selection was done using $\triangle \mathrm{AICC}$ and parsimony. 


\section{Supplementary Files}

This is a list of supplementary files associated with this preprint. Click to download.

- SupportinginformationOecologia.pdf 